J. Lake Sci. (湖泊科学), 2014, 26(4): 529-534

http: //www. jlakes.org. E-mail : jlakes@niglas.ac.cn

(C) 2014 by Journal of Lake Sciences

\title{
鄱阳湖泄流能力分析
}

\author{
赖锡军, 黄 群, 张英豪,万荣荣,姜加虎
}

(中国科学院南京地理与湖泊研究所湖泊与环境国家重点实验室, 南京 210008)

摘 要: 鄱阳湖近年低枯水位频繁发生, 引起了人们广泛的关注. 鄱阳湖作为吞吐型湖泊, 通过狭长的湖口水道与长江自 然相通, 其水力特性直接影响着长江与鄱阳湖的相互作用关系. 基于水力学方法, 提出湖泊泄流能力的概念, 并采用湖泊 水文观测数据, 研究了鄱阳湖的泄流能力特征及其近年的演变过程. 结果表明, $2000 \mathrm{~s}$ 之前鄱阳湖泄流能力基本维持不 变,之后迅速提高,近年开始趋于稳定. 泄流能力的显著提高改变了鄱阳湖与长江相互作用的水力特性,从而影响了鄱阳 湖的水量平衡, 加剧了近年枯水情势. 研究表明, 大规模采砂是鄱阳湖泄流能力变化的主因, 应加强鄱阳湖采砂管理.

关键词: 水位;泄流能力; 鄱阳湖;采砂;水力学方法; 长江

\section{Discharge capacity analysis on Lake Poyang}

LAI Xijun, HUANG Qun, ZHANG Yinghao, WAN Rongrong \& JIANG Jiahu

( State Key Laboratory of Lake Science and Environment, Nanjing Institute of Geography and Limnology, Chinese Academy of Sciences, Nanjing 210008, P. R. China)

\begin{abstract}
The recently frequent low water level in Lake Poyang attracted wide public attention. As an open lake, Lake Poyang is naturally connected with the Yangtze River via the Hukou Waterway. The interactions between the Yangtze River and the Lake Poyang are directly affected by the flow characteristics of the Hukou Waterway. The discharge capacity is introduced to represent the ability to convey water away using the hydraulic approach. The discharge capacity and its change is investigated here. Results show that: The discharge capacity was stable before 2000s and thereafter it rapidly increased. Its remarkable increase altered the interaction between the Yangtze River and Lake Poyang, leading to the recent severe drought regime. Large-scale sand dredging in Lake Poyang is attributed to be the cause of this increase. The management for sand dredging should be strengthened for conserving the water resources in Lake Poyang.
\end{abstract}

Keywords: Water level; discharge capacity; Lake Poyang; sand dredging; hydraulic approach; Yangtze River

鄱阳湖是我国第一大淡水湖泊,湖泊水量的维持对区域社会经济发展以及环境和生态的保护具有重要 价值. 但是近 10 年来,鄱阳湖多次出现季节性干旱,低枯水位持续,湖泊水面出现持续减小的趋势. 研究显 示, 鄱阳湖水位, 特别是枯水期水位不断走低,2006 年以来的湖泊水位呈现突变的特征 ${ }^{[1-2]}$. 湖泊水量的这些 变化,已经对鄱阳湖湖区居民生产生活以及湖泊环境和生态带来了严重的影响 ${ }^{[3]}$. 为了分析湖泊水量变化, 特别是枯水形成的原因,研究人员利用不同方法从不同角度分析了气候变化和三峡工程等重大水利工程对 鄱阳湖水量 (或水位) 的影响 ${ }^{[4-10]}$.

鄱阳湖承纳自身流域内的贑江、抚河、信江、饶河、修水五河及未控湖周区间来水,调蓄后经由北部湖口 水道北注长江 (图 1). 在长江主汛期, 江水高涨, 可倒灌鄱阳湖. 鄱阳湖吞吐长江, 为典型的吞吐型湖泊. 作为 鄱阳湖出流的唯一通道, 狭长形的湖口水道充当了长江与鄱阳湖之间复杂相互作用的桥梁. 鄱阳湖水量维 持主要取决于鄱阳湖流域自身来水与湖口出流的消涨. 一般地,长江水位较低的枯水期鄱阳湖湖泊水量输 人输出基本平衡, 水位随流域来水消涨变化, 即表现出流域来多少水,湖泊就流出多少水. 若流域来水不变, 则湖口水道出流水力特征就成为维持鄱阳湖水位 (或水量) 的关键因素. 研究湖泊出流水力特征参数的变化

* 国家重点基础研究发展计划 “973” 项目 (2012CB417000) 和国家自然科学基金项目 (41071021) 联合资助. 2013-05-24收稿;2013-09-16 收修改稿. 赖锡军(1977 ), 男, 博士, 副研究员; E-mail:xjlai@ niglas. ac. cn. 


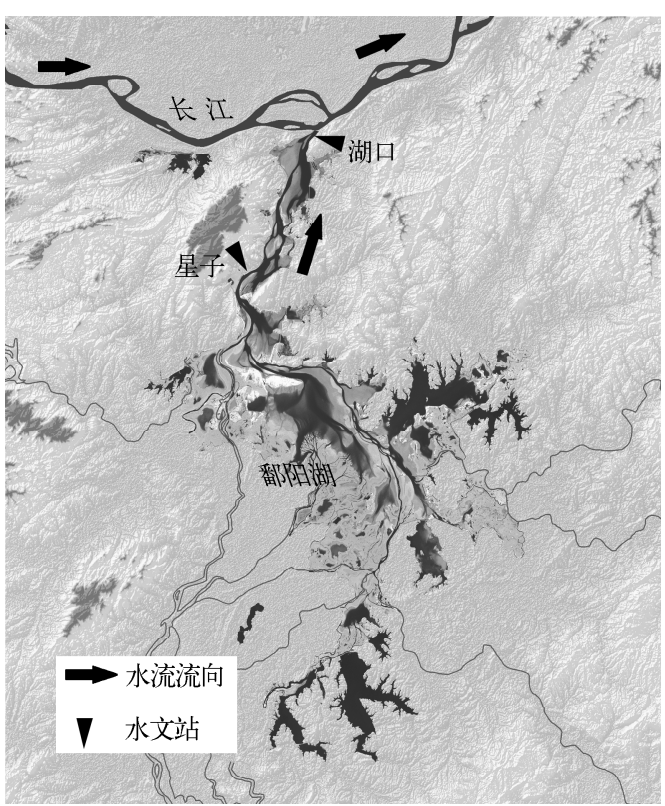

图 1 鄱阳湖与长江的连通关系

Fig. 1 The connection between Lake Poyang and the Yangtze River

可在一定程度上帮助人们理解鄱阳湖近年频繁发生 枯水的原因.

本文基于水力学原理提出了湖泊泄流能力这一 概念来反映湖泊出口泄流的水力特性, 并采用长序 列的水位和流量数据分析了鄱阳湖泄流能力特征及 其变化,分析讨论了鄱阳湖泄流能力变化对湖泊水 量平衡的影响以及大规模采砂与鄱阳湖泄流能力变 化的关联性.

\section{1 湖泊泄流能力及其分析方法}

对河渠均匀流, 由水力学中著名的谢才公式可 计算出其平均流速:

$$
V=C \sqrt{R J}
$$

式中, $V$ 为流速, $C$ 为谢才系数, $R$ 为水力半径, $J$ 为河 渠水力坡降.

则通过河渠的总流量 $(Q)$ 可表示为:

$$
Q=V A=C A \sqrt{R J}
$$

式中, $A$ 为河渠过水断面面积.

一般地, 湖泊出流都有相应的泄水通道. 为了采 用式 (2) 计算湖泊的泄流量, 需要确定湖泊出流通道 的水力坡降. 湖泊出流的水位落差可根据湖泊代表站水位 $Z_{\mathrm{C}}$ 及其出口的水位 $Z_{0}$ 来近似计算. 假设湖泊出流 通道长度为 $L$, 则湖泊出流的水力坡降 $J$ 可表达为:

$$
J=\frac{Z_{\mathrm{C}}-Z_{0}}{L}=\frac{\Delta Z}{L}
$$

式中, $\Delta Z$ 为湖泊出流水位落差.

若将湖泊出流量与水位落差的平方根比值定义成湖泊的泄流能力 $k$, 即:

$$
k \equiv \frac{Q}{\sqrt{\Delta Z}}=\frac{C A \sqrt{R}}{\sqrt{L}}=\frac{K}{\sqrt{L}}
$$

式中, $K=C A \sqrt{R}$ 在水力学中常被称为流量模数.

湖泊泄流能力 $k$ 为在自由出流条件下由单位水位落差驱动引起的湖泊下泄流量大小. 公式 (4) 表明, 湖 泊泄流能力仅与谢才系数 $C$ 和湖泊出流通道的几何要素相关. 为了确定湖泊的泄流能力, 需要确定谢才系 数、过水断面面积、水力半径和出流通道长度等. 湖泊泄流能力的变化体现了湖泊出流通道几何要素和床面 粗鉌度等特征的演变.

谢才系数是一个量纲为 $\mathrm{m}^{0.5} / \mathrm{s}$ 的系数, 不是常数, 与过水断面形状和床面粗鋉度等有关. 在河道水力计 算中常用曼宁公式计算, 即:

$$
C=\frac{1}{n} R^{\frac{1}{6}}
$$

式中, $n$ 为曼宁䊁率系数, 是衡量河渠床面粗糙度对水流影响的一个综合性系数, 与底质形态和质地等有关. 由于曼宁公式使用起来简单方便,被广泛应用于天然河道的水力计算.

将式(5) 代人式(4), 可得: 


$$
k=\frac{A R^{\frac{2}{3}}}{n \sqrt{L}}
$$

从公式 (6) 可以看出,湖泊泄流能力可综合反映湖泊出口过水断面形状 (过水面积 $A$ 和水力半径 $R$ ) 和 通道长度等几何要素以及河渠床面粗䊅度 $(n)$ 等特性对湖泊出流的影响. 但是, 该公式要求水流阻力系数处 于阻力平方区, 即紊流粗䊁管区沿程阻力系数与雷诺数无关, 只与壁面的相对粗糙度有关. 当条件满足时, 该公式不仅适用于河渠的恒定均匀流,而且在缓变流和非恒定流中也可近似地应用.

糙率不是一个可直接测定的物理量. 在河渠水力计算中, 经常由实测的水位和流量数据来率定. 而且对 于天然河道,其水力半径和过水断面面积的计算都需要有大量的数据支撑. 直接由式(6)来计算湖泊泄流能 力在有些情况下并不简便.

对于常规水文数据可获取的湖泊,还可以基于常规的水位和流量观测数据采用式(4)来拟合确定.

本文基于 1955-2011 年长时间序列常规水文观测数据,估算鄱阳湖的泄流能力. 根据式 (7), 以鄱阳湖 湖口流量作为湖泊总泄流量, 湖口水位数据作为湖泊出口水位,星子站水位数据代表湖泊水位. 在洪水期长 江水位高涨时,会顶托鄱阳湖,阻碍湖水下泄, 甚至倒灌鄱阳湖. 这时期的湖泊水位高, 水深大, 水流非恒定 性特征明显,水力条件明显偏离了谢才公式所要求的恒定均匀流; 而且该时期, 星子一湖口水位落差很小,微 小的水力坡降可引起巨大的流量变化, 采用这些数据可能引人较大的不确定误差. 而在历年 $1-3$ 月, 长江 处于较低的水位, 五河来水经由湖口水道下泄, 逐日流量变化较为稳定, 基本满足恒定泄流条件. 因此, 文中 选用了历年 $1-3$ 月的水文观测数据来估算鄱阳湖泄流能力,采用 $14 \mathrm{~m}$ 以下所有流量数据来检验估算值的 可靠性.

从泄流能力 $k$ 的表达式可以看出, 它不是一个常数, 而是关于䊁率 $n$ 、过水断面面积 $A$ 、水力半径 $R$ 和出 流通道长度 $L$ 的函数. 其中, $n$ 主要反映床面粗䊁度等特性, 在天然河道中变化范围很小, 可认为基本保持稳 定. 若 $L$ 不变,则 $k$ 可由过水断面的 $A$ 和 $R$ 来确定. 又注意到 $A$ 和 $R$ 都是关于水位 $Z$ 的函数, 且呈单调递增 的关系, 即水位上升, $A$ 和 $R$ 也随之增大. 为了使结果应用更为简便, 可将 $k$ 的函数关系简化,用湖泊出口水 位来描述过水断面几何要素, 即将 $k$ 看成仅是关于湖泊出口水位 $Z$ 的函数: $k=f(Z)$.

湖泊出流通道的变化将改变湖泊泄流能力, 从而影响到湖泊水量的平衡. 因此, 湖泊泄流能力 $k$ 的估算 可服务于湖泊水量平衡的计算. 分析湖泊泄流能力的长历时变化, 可帮助人们去认识和理解湖泊水量的 变化.

\section{2 结果}

鄱阳湖泄流能力与湖口水位呈单调上升的曲线关系. 湖口水位越高, $k$ 越大. $k$ 随水位上升的增速呈指 数或幂指数关系快速上升. $2000 \mathrm{~s}$ 之前, 鄱阳湖泄流能力与湖口水位关系较为稳定, 且湖口水位与泄流能力 基本呈一一对应的关系. 采用幂函数拟合得到: $k=0.72 Z^{3.72}$, 其确定系数 $R^{2}$ 为 0.95 (图 2). 但是 2000s 以后, 鄱阳湖泄流能力开始发生调整. 鄱阳湖泄流能力与湖口水位的关系开始逐步偏离原来长期形成的稳定曲线 关系. 2000s 初是一个变化的转折点. 从图 2 可以明显看出, 2002-2007 年,相同湖口水位条件下鄱阳湖泄流 能力开始逐年提高. 2007 年之后, 同一湖口水位条件下的泄流能力有了明显上升,基本上已完全偏离原来的 历史曲线关系. 2008-2011 年间湖口不同水位对应的泄流能力散点数据 (图 2 ) 表明,鄱阳湖泄流能力有逐 步稳定的趋势. 这时期的泄流能力与湖口水位关系可以用指数函数来很好地拟合, 方程为 $k=497.93 \mathrm{e}^{0.26 Z}$, 其确定系数 $R^{2}$ 为 0.89 .

\section{3 讨论}

\section{1 鄱阳湖泄流能力变化检验及对湖泊水量平衡的影响}

为了检验鄱阳湖泄流能力分析结果的合理性并进一步探讨其对鄱阳湖水量平衡的影响, 本文采用 1955-2000年和 2008-2011 年两个阶段的拟合公式,分别回代计算了湖口水位 $14 \mathrm{~m}$ 以下的湖口流量(其中 也包含了 1-3 月间用于计算拟合公式的部分数据). 计算值与实测值比对结果如图 3 所示. 可以看出, 根据 星子站和湖口水位,各阶段拟合的湖泊泄流能力公式都较为准确地测算了各自时段内的湖口流量. 而当将 


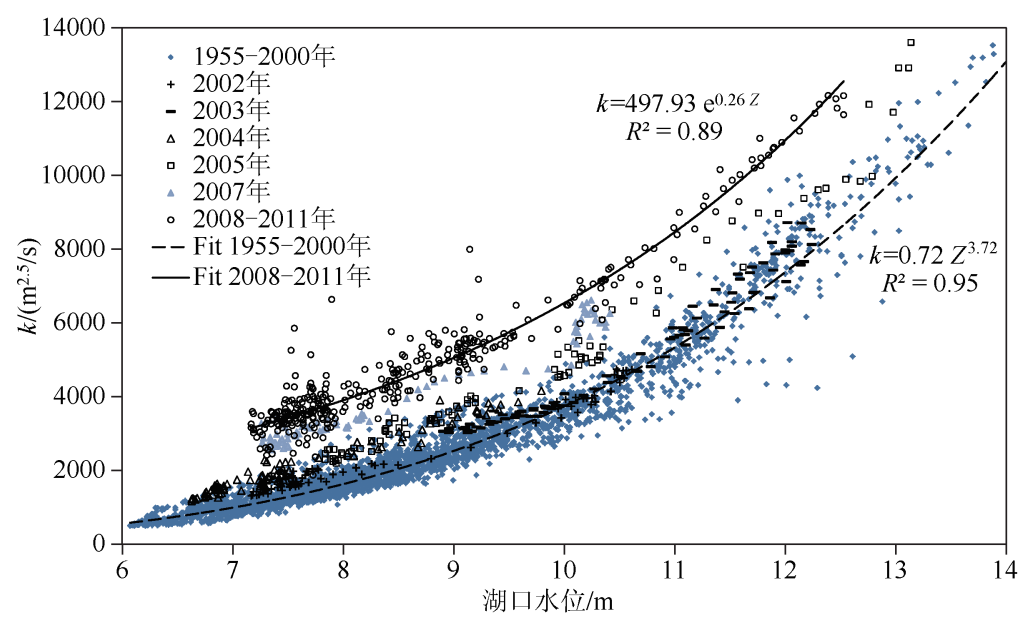

图 2 鄱阳湖泄流能力与湖口水位关系及其变化

Fig. 2 The relationship of lake discharge capacity in Lake Poyang with water level in Hukou Waterway and its change

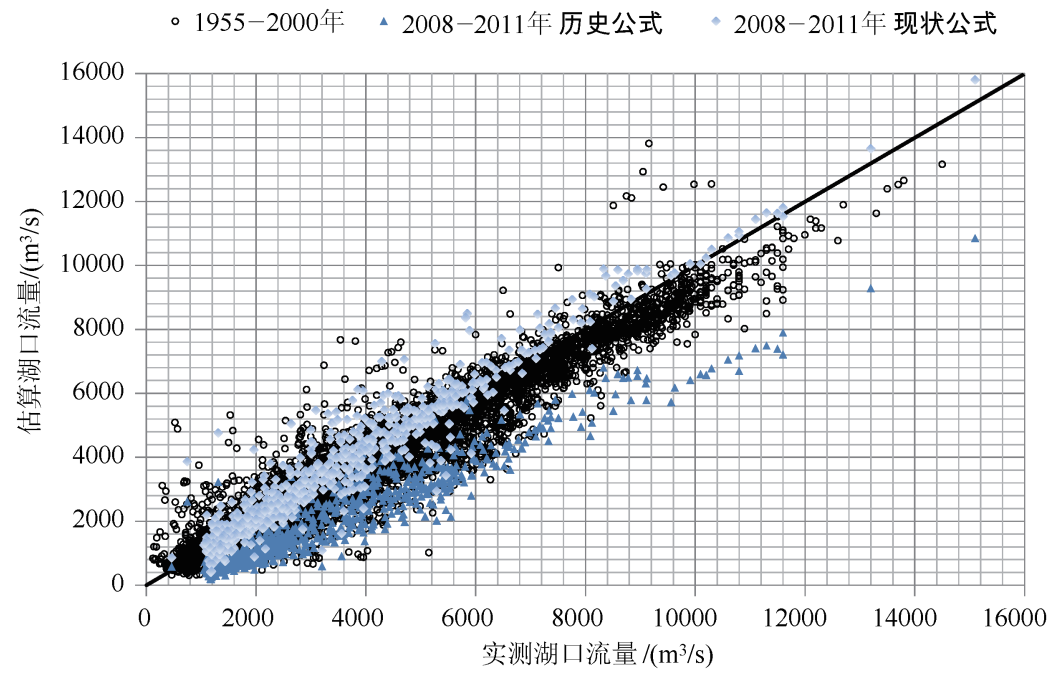

图 3 湖口流量估算检验

Fig. 3 Validation of the calculated lake discharges against the measured discharges in Hukou Waterway

1955-2000 年的鄱阳湖泄流能力 (历史公式) 用于计算 2008-2011 年的湖口流量时,预测的流量明显偏低. 这不仅说明本文湖泊泄流能力分析结果的合理性, 同时也间接地证实了湖泊泄流能力改变已引起湖泊水量 的变化. 对相同的星子站和湖口水位, 由于湖泊泄流能力的增强, 现在的湖口流量要明显高于历史时期的流 量, 即湖泊蓄水能力降低, 使得湖水快速下泄, 湖泊水位降低. 从另一个角度来看, 由于湖泊泄流能力显著增 强, 维持同等下泄流量所需的星子一湖口水位落差要小得多. 考虑到湖口水位决定于长江与五河的合成流 量,因此,如若流域来水与过去相同,则湖泊水位 (星子站) 必然较历史同期要明显偏低.

\section{2 采砂对鄱阳湖泄流能力变化的可能影响}

从前文分析可以知道, 鄱阳湖泄流能力在 $2000 \mathrm{~s}$ 初的 10 年发生了显著的变化. 其中可能的原因无外乎 
过水断面形态和粘率的变化. 与过水断面形态相比, 糙率在可变化的范围内是一个相对小量. 由此推断,湖 口水道的过水断面形态必然发生了重大变化. 然而, 天然条件下鄱阳湖的湖口水道处既有冲又有淤, 冲淤变 化不明显, 全湖年平均冲刷率在 $2 \sim 3 \mathrm{~mm}$ 左右 ${ }^{[11-13]}$. 考虑到 1955-2000 年间的鄱阳湖泄流能力与湖口水位 关系曲线,这种缓慢的自然演变对鄱阳湖湖口水道的影响也应该是个小量.

湖泊泄流能力的显著变化应主要是由近 10 年大规模的采砂改变湖口水道过水断面几何要素引起的. 在 1990s 末期, 为确保防洪和航运的安全, 沿江各个省份逐步禁采长江水域江砂. 国务院公布的《长江河道 采砂管理条例》也规定从 2002 年 1 月 1 日起开始禁止采砂. 鄱阳湖泥沙资源丰富, 大规模采砂船自 2000s 开 始云集鄱阳湖,采砂最密集的区域就集中于鄱阳湖北部都昌 (吴城)一湖口一带的洪道主槽及其周边. 虽然没 有完整的采砂资料和地形变化资料,但是从相关的独立研究和部门的不完全统计资料来看,湖口水道的河 床变化是非常显著的. de Leeuw 等 ${ }^{[11]}$ 利用 2006 年遥感数据估算了出湖运砂船的数量并间接核算得到了鄱 阳湖的采砂量, 结果表明, 年采砂量高达 $4.48 \times 10^{8} \mathrm{t}$, 均分到 $400 \mathrm{~km}^{2}$ 的湖口水道 (含吴城部分) 上, 意味着床 底高程每年将下降 $59 \mathrm{~cm}$. 另外, 据九江市海事等部门统计 ${ }^{[14]}, 2005-2007$ 年间实际采砂量为 $2.3 \times 10^{8} \sim$ $2.9 \times 10^{8}$ t. 两者对照可以发现, 即使极其保守地估计, 年采砂规模也高达上亿吨.

文献[13] 的实测地形数据表明,与 1999 年相比,2008 年湖口水道内的星子断面平均湖底高程下降 $2.4 \mathrm{~m}$, 屏峰断面高程平均下降 $4.15 \mathrm{~m}$. 卫星影像图的对比 (图 4) 可证实,2000 年以来鄱阳湖湖口水道的河道形态 发生了明显变化. 虽然 1999 年和 2010 年两幅卫星影像对应的湖口水位仅相差约 $6 \mathrm{~cm}$,但是从 2 张卫星影像 中可以看出,2010 年湖口水道主槽横向明显展宽,断面展宽从几十米到上千米不等,且有明显的人工挖掘形 成的锯齿形洲滩边缘. 这说明采砂不仅引起河床下切,而且使渠道横向展宽,洲滩面积缩小. 因此, 可推断, 采砂引起的湖口过水断面显著变化是造成湖口水道的过水能力明显提高的主因.

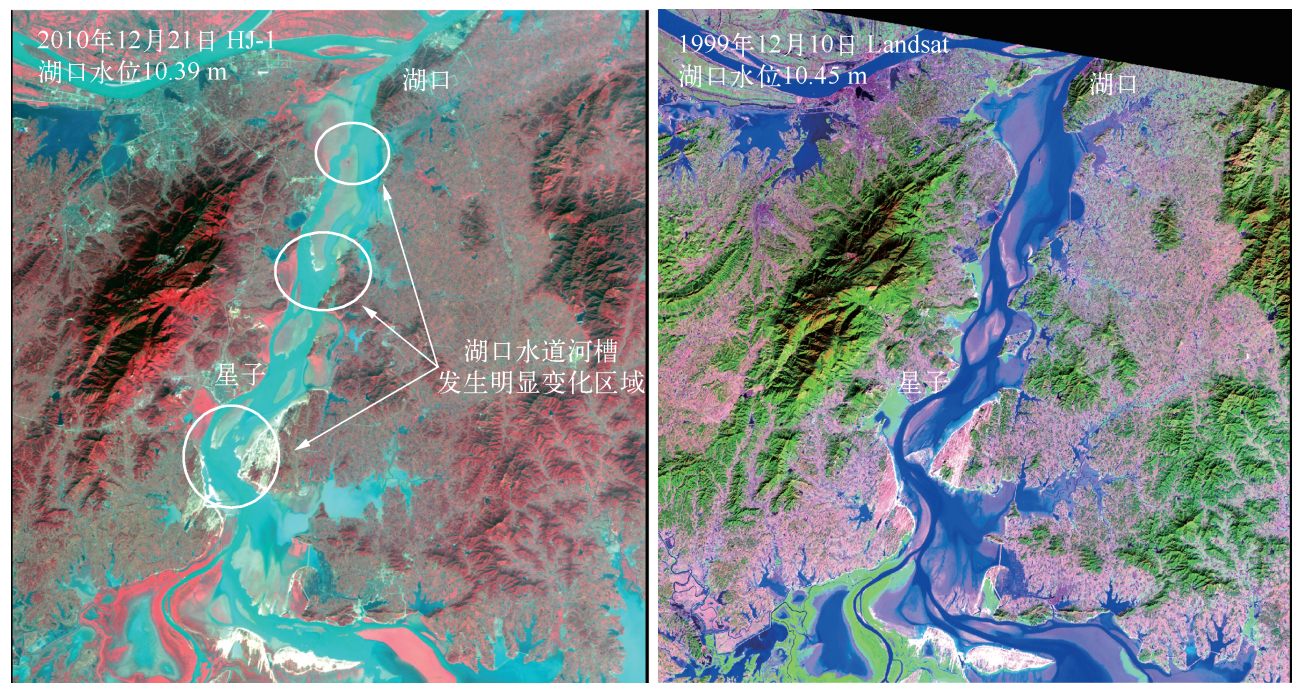

图 4 采砂引起的鄱阳湖湖口水道水面变化

Fig. 4 The remote sensing water surface change caused by sand dredging in the Hukou Waterway in Lake Poyang

\section{4 结语}

本文提出了湖泊泄流能力的概念且给出了其数学表达式. 并以鄱阳湖为例, 研究了其泄流能力特征及 其演变过程, 分析讨论了泄流能力变化对鄱阳湖水量平衡的影响以及大规模采砂与湖泊泄流能力的关联 性. 结果表明: (1) 2000s 之前鄱阳湖泄流能力基本维持不变, 之后鄱阳湖泄流能力逐年明显提高, 近年开始 趋于稳定. (2) 泄流能力的变化改变了鄱阳湖与长江相互作用的水力特性, 从而使得鄱阳湖水量平衡发生 
了变化,加剧了近年的枯水情势. (3) 大规模采砂是鄱阳湖泄流能力变化的主因,应加强鄱阳湖采砂管理.

鄱阳湖泄流能力, 即出流水力特性也影响着长江与鄱阳湖的泥沙与营养盐等物质的交换关系. 泄流能 力的显著改变, 就意味着江湖相互作用关系将发生根本性的变化. 即使鄱阳湖自身流域来水和长江来水不 变, 江湖相互作用也不可能恢复到过去的关系, 而是形成一个新的平衡点. 因此, 翻阳湖相关科学研究和管 理措施制定必须立足于新的江湖关系格局.

\section{5 参考文献}

[ 1 ] Liu Y, Wu G, Zhao X. Recent declines in China's largest freshwater lake: trend or regime shift? Environmental Research Letters, 2013, 8(1): 014010 .

[2] 闵 骞,占腊生. 1952-2011 年鄱阳湖枯水变化分析. 湖泊科学, 2012,24(5):675-678.

[ 3 ] 杨桂山. 长江水问题基本态势及其形成原因与防控策略. 长江流域资源与环境,2012,(7):9.

[ 4 ] Guo H, Hu Q, Zhang Q et al. Effects of the Three Gorges Dam on Yangtze River flow and river interaction with Poyang Lake, China: 2003 -2008. Journal of Hydrology, 2012, 416/417 : 19-27.

[ 5] 赖锡军, 姜加虎, 黄 群. 三峡工程蓄水对鄱阳湖水情的影响格局及作用机制分析. 水力发电学报, 2012,31(6): 132-136.

[6 ] Zhang Q, Li L, Wang YG et al. Has the Three-Gorges Dam made the Poyang Lake wetlands wetter and drier? Geophysical Research Letters, 2012, 39(20): L20402.1-L20402.7.

[ 7 ] Guo H, Hu Q, Jiang T. Annual and seasonal streamflow responses to climate and land-cover changes in the Poyang Lake basin, China. Journal of Hydrology, 2008, 355(1/2/3/4) : 106-122.

[8] 汪迎春, 赖锡军, 姜加虎等. 三峡水库调节典型时段对鄱阳湖湿地水情特征的影响. 湖泊科学, 2011, 23(2): 191-195.

[9] 方春明,曹文洪,毛继新等. 鄱阳湖与长江关系及三峡蓄水的影响. 水利学报,2012,43(2):175-181.

[10] 梁忠民, 郭 彦, 胡义明等. 基于 copula 函数的三峡水库预泄对鄱阳湖防洪影响分析. 水科学进展, 2012,23 (4) : $485-492$.

[11 de Leeuw J, Shankman D, Wu G et al. Strategic assessment of the magnitude and impacts of sand mining in Poyang Lake, China. Regional Environmental Change, 2010, 10(2) : 95-102.

[12］马逸麟,熊彩云, 易文萍. 鄱阳湖泥沙淤积特征及发展趋势. 资源调查与环境, 2003,24(1):29-37.

[13] 闵 寒,时建国,闵 聑. 1956-2005 年鄱阳湖人出湖悬移质泥沙特征及其变化初析. 水文,2011,31(1):54-58.

[14] 陈前金.九江市对鄱阳湖采砂实行统一管理初见成效. 江西水利科技,2010,36(2):147-148. 